\title{
НАУЧНО-ТЕХНИЧЕСКИЙ ПРОГРЕСС КАК ФАКТОР ОППОРТУНИСТИЧЕСКОГО ПОВЕДЕНИЯ ПОСТАВЩИКОВ
}

\author{
(c) 2020 Лебедев Константин Николаевич \\ доктор экономических наук, доцент, профессор Департамента экономической теории \\ Финансовый университет при Правительстве Российской Федерации, Россия, Москва \\ E-mail: KNLebedev@fa.ru \\ ORCID: https://orcid.org/0000-0002-4846-8097
}

В настоящей статье рассматриваются обстоятельства, делающие участие в исполнении по госзаказу исследований и разработок (ИиР) значительно более привлекательным для недобросовестных исполнителей, чем участие в поставках для государственных нужд других товаров. В статье также рассматриваются условия, позволяющие недобросовестным исполнителям ИиР пользоваться данными обстоятельствами, главным из которых является отсутствие квалифицированного госзаказчика Ии Р.

Ключевые слова: научно-технический прогресс, фальсификация ИиР, самогосзаказ ИиР, коррупция в ИиР.

Оппортунистическое поведение, или уклонение партнеров от добросовестного исполнения контрактов с целью необоснованного обогащения, с некоторых пор стало объектом пристального внимания науки, прежде всего экономической теории. В настоящей статье объектом исследования выступает оппортунистическое поведение самой науки при исполнении госзаказа, интерес к которому, очевидно, является обоснованным. Его огромные масштабы были вскрыты в период проведения кардинальных реформ в сфере исследований и разработок (ИиР) (2011-2015 гг.). Эксперты, опираясь на материалы проверок, заговорили чуть ли не о нулевой эффективности бюджетных расходов на ИиР в стране - похожий вывод в 2011 г. сделала, например, газета «Ведомости» [26]. Ей соответствует крайне низкая результативность ИиР (включая получение отрицательных результатов), говорящая о масштабной экономии исполнителей на затратах на ИиР, или крайней прибыльности ИиР для недобросовестных исполнителей. Об этой прибыльности свидетельствует желание поставщиков ИиР платить чиновникам крайне высокие откаты (откат выплата чиновнику за доступ к исполнению госзаказа, устанавливаемая в процентах от его стоимости), которое за период реформ только усилилось. Так, на IX Международном Форуме «Инновационное развитие через рынок интеллектуальной собственности» (г. Москва, 7 апреля 2017 г.) было отмечено, что за последние 20 лет сфера исследований и разработок (ИиР) стала одной из наиболее коррупциогенных областей и реальной угрозой национальной безопасности, если в 2007-2009 гг. откаты составляли треть всех бюджетных расходов на ИиР, то в настоящее время доходят до половины [20]. Заметим, что речь идет не о максимальных ставках отката, а о доле откатов в общей величине расходов бюджета на науку. Возникает вопрос, что делает научно-технический прогресс, выступающий результатом ИиР, таким эффективным инструментом необоснованного обогащения недобросовестных исполнителей соответствующих работ.

Для ответа на поставленный выше вопрос необходимо установить обстоятельства, создающие дополнительные возможности для необоснованного обогащения на поставках по госзаказу ИиР по сравнению с поставками других товаров, и факторы, позволяющие недобросовестным поставщикам воспользоваться этими обстоятельствами. Госзаказ ИиР трактуется в настоящей статье в самом широком смысле. К ним, помимо собственно закупок ИиР по госконтрактам, относятся грантовое финансирование ИиР из бюджета или средств государственных научных фондов, бюджетное финансирование выполнения госзадания в сфере науки, финансирование ИиР государственными организациями из внебюджетных источников, закупки ИиР госкомпаниями.

Рассмотрим обстоятельства, создающие дополнительные возможности для недобросовест- 
ного обогащения при поставках для государственных нужд именно Ии Р.

1. Сложность для заказчика ИиР оценки научной ценности их результатов. Наличие этого обстоятельства объясняется уникальным характером Ии Р.

Установить наличие (степень) новизны исследования, т.е. проверить качество результатов ИиР, значительно сложнее, чем проверить качество любого другого товара, закупаемого для государственных нужд, например, машин, оборудования, строительных работ. Об этом говорит, в частности, отсутствие до настоящего времени общепризнанных методик оценки результатов интеллектуальной деятельности (РИД), в отличие, например, от методик оценки качества тех же строительных работ. Как отмечает Д.В. Трошин, проблема оценки качества научных РИД, и фундаментальных, и прикладных, остается дискуссионной, несмотря на обилие работ на эту тему, споры идут, прежде всего, вокруг используемых для оценки параметров (наличие исследования, актуальность, соответствие тематике, практическая значимость, широта темы, величина риска и т.д.) и методов (система оценки, шкала оценки, весовые коэффициенты и т.д.), при этом субъективность и произвольность в процессе оценки не изживаются, а в России вообще отдается предпочтение методу оценивания коллегами (peer review) в виде анонимного рецензирования или коллективного обсуждения [24, c. 51-54].

Сложность для заказчика установить новизну исследования позволяет недобросовестным исполнителям ИиР обогащаться путем их фальсификации. Фальсификация - подделка, подмена настоящего ложным [2], т.е. в данном случае подмена настоящего исследования ложным исследованием. Фальсификация ИиР позволяет их исполнителю обогащаться за счет экономии на расходах на исследование. Фальсификация особенно распространена при госзаказе ИиР на основе конкурсного отбора заказчиком инициативных научных проектов, прежде всего при поддержке научных проектов государственными научными фондами, подготовке диссертаций обучающимися на бюджетной основе.

Фальсификаций ИиР выступает, прежде всего, плагиат - умышленное присвоение авторства чужих произведений, изобретений или технологических решений [25]. Плагиат считается самым распространенным видом интеллек- туального мошенничества, ставшим уже частью культуры научно-образовательного сообщества [17]. В нашей стране плагиат внедрялся в практику научной деятельности через подготовку диссертаций. Неслучайно в России «вольное сетевое сообщество экспертов, исследователей и репортеров, посвящающих свой труд разоблачениям мошенников, фальсификаторов и лжецов» в области науки, получило название «Диссернет», и в своем анонсе подчеркивает, что противодействуют незаконным махинациям и подлогам в особенности в процессе защиты диссертаций и присвоения ученых степеней [3]. На Западе расцвет плагиата в ИиР связан, прежде всего, с грантовым финансированием науки. В 1970-1980-е гг. западную науку просто захлестнула связанная с ним волна плагиата. До сих пор вспоминают ряд наиболее нашумевших случаев. Так, Виджайя Саман, индийский студент Йельского медицинского колледжа, присвоил результаты из научной статьи своего коллеги, получил под свое исследование грант в размере 100 тыс. долл. США от Национальных институтов здравоохранения США, отчитавшись за него одиннадцатью статьями, оказавшимися плагиатом [Примеры мошенничества..., 2007].

Особую популярность приобрел «самоплагиат», когда, например, при поддержке научных фондов публикуются статьи, представляющие собой материал собственных диссертаций или других научных работ их авторов 10-15-летней давности.

Современная компьютерная техника, пришедшая на помощь выявлению плагиата, все же не способна решить проблему плагиата, так как противостоит лишь краже текстов, а не заключенных в них идей или технических решений. В случаях непрямого цитирования, как и до появления компьютерных программ антиплагиата, выявление плагиата продолжает оставаться весьма сложным делом, оказывающимся под силу, как правило, лишь самим авторам некорректно заимствованных научных результатов.

Одним из популярных способов фальсификации ИиР, факт использования которого весьма сложно установить, является экстраполяция результатов одних ИиР на другие Ии Р. Первые громкие разоблачения подобных фальсификаций также имели место на Западе. Вспоминают случай Дж. Дарси, ученого из Национального института крови, сердца и легких, прослывшего самым талантливым из молодых кардиологов 
США, который в 1977-1981 гг. лично и в соавторстве опубликовал 18 статей в главных биомедицинских журналах, а также около ста рефератов, глав в монографиях, писем, рецензий и т.д. по проблемам клинической и экспериментальной кардиологии. Как выяснилось, «методом» Дж. Дарси и его коллег стала экстраполяция данных одних исследований на другие, например результаты экспериментов над собаками, полученные в течение нескольких часов, применялись к исследованиям, якобы проводившимся в течение двух недель, результаты недельного эксперимента над крысами переносились на опыты, которые должны были осуществляться 1,5 года. О сложности выявления подобных фальсификаций говорит продолжительность «исследований» Дж. Дарси. Погорел он, в частности, на данных о 17-летнем юноше, страдавшем редким сердечным недугом, который, согласно анамнезу, имел 4 детей возрастом 4, 5, 7 и 8 лет [18].

Еще один способ фальсификации ИиР - лженаучные исследования. Они крайне сложно поддаются разоблачению при том, что имеют свойство завораживать чиновников и других лиц, от которых зависит выделение средств на соответствующие исследования. Их яркий пример в России - дело «Петрикгейт». В 2006 г. был провозглашен старт партийной программы Единой России «Чистая вода», целью которой было обеспечение всего населения России качественной питьевой водой. В 2007 г. победителем партийного конкурса на лучший фильтр для питьевой воды становится неизвестная компания ООО «Холдинг «Золотая формула», принадлежащая В. Петрику, одновременно выступившему разработчиком этого фильтра. При этом В. Петрик позиционировал себя как автор множества научных открытий, носящих сенсационный характер. Еще в 2006 г. в Нижегородской области был запущен пилотный проект по оснащению фильтрами Петрика социальных учреждений, финансируемый за счет бюджета области. Одно время на финансирование государственной целевой программы «Чистая вода», связанной с установкой фильтров Петрика, предполагалось выделить даже 15 трлн. руб. Однако в 2009 г. главный редактор журнала «Водоснабжение и канализация» С. Финаев на основе профессиональных исследований пришел к выводу, что фильтр Петрика отличается от обычных сорбционных фильтров лишь в несколько раз завышен- ной ценой и может быть опасен для здоровья, а председатель комиссии по борьбе с лженаукой Э. Кругляков установил, что научные открытия В. Петрика открытиями не являются, а некоторые из его заявлений противоречат твёрдо установленным научным данным, в связи, с чем являются лженаучными. В результате последовавшего скандала проект «фильтр Петрика» был остановлен [14].

2. Наличие системы госзаказа на основе конкурсного отбора инициативных научных проектов и сложность для заказчика отбора перспективных проектов, обусловленная уникальностью Ии Р. Данное обстоятельство позволяет исполнителю ИиР в максимальной степени использовать для незаконного обогащения первое обстоятельство, так как облегчает фальсификацию ИиР за счет утверждения заказчиком удобных для нее тем.

3. Наличие существенного риска недостижимости оговоренных в госзаказе результатов ИиР или их превращения в бесперспективные (для последующего использования) по причинам, не зависящим от исполнителя, и значительная сложность для заказчика выявления факта превращения результатов осуществляемых ИиР в недостижимые или бесперспективные. Важно отметить, что неполучение оговоренных результатов ИиР или их превращение в бесперспективные не по вине исполнителя подразумевает полную оплату заказчиком произведенных работ [12]. Рассматриваемое обстоятельство порождается интеллектуальным характером научной деятельности. Во-первых, он придает научной деятельности творческий характер, обусловливающий ее слабую предсказуемость. Это и создает значительную вероятность, как неполучения исполнителем требуемых результатов ИиР не по его вине, так и получения лучших результатов конкурентами, что превращает оговоренные в госзаказе результаты ИиР в бесперспективные. Как отмечает Д.В.Трошин, научные РИД имеют высокую неопределенность успеха, облика и коммерческих характеристик потенциальной коммерческой продукции [24, с. 51].

Есть данные, что в мире в предпринимательском секторе науки только $12 \%$ идей, т.е. НИР, завершаются концепциями для новых продуктов, и только $23 \%$ этих концепций, т.е. ОКР, завершаются разработкой продуктов, которые реально выводятся на рынок [8]. Это значит, что только $2,8 \%(0,12 * 0,23 * 100)$ идей новых продуктов, воз- 
никших в предпринимательском секторе, превращаются в новые товары, т.е. 97,2\% (100-2,8) ИиР здесь заканчиваются неудачей. Даже с учетом того, что в этот процент входят ИиР, закончившиеся неудачей по вине исполнителей, в том числе сторонних, и ИиР с перспективными результатами, не использованными из-за ошибок в инновационной деятельности, мы имеем огромный процент работ, не завершившихся для заказчиков ничем, но оплаченных исполнителям.

При заказе других товаров для госнужд вероятность неполучения оговоренных результатов или их превращения в бесперспективные для использования не по вине поставщика крайне низка.

Во-вторых, интеллектуальный характер научной деятельности обусловливает ее скрытость от внешнего наблюдения, непрозрачность. Это крайне затрудняет наблюдение заказчика за ходом исследований как исполнителя, так и конкурентов, что и обусловливает значительную сложность для него выявления факта как недостижимости оговоренных в госзаказе результатов ИиР, так и их превращения в бесперспективные для дальнейшего использования. При заказе других товаров для госнужд заказчик может легко отслеживать как ход исполнения заказа, так и успехи конкурентов, своевременно прекращать его исполнение в случае технической или коммерческой неудачи.

Рассмотренное выше обстоятельство используется для недобросовестного обогащения, главным образом, при госзаказе ИиР по директивным тематикам. Оно позволяет исполнителю ИиР, как правило, первому обнаруживающему недостижимость или бесперспективность результатов ИиР, скрывая данный факт от заказчика, необоснованно затягивать неудачные ИиР, получая под них финансирование, а свои расходы, связанные с продолжением работ, сводя к минимуму.

Данное обстоятельство вкупе со вторым позволяет недобросовестному исполнителю получить госзаказ на ИиР с заведомо недостижимыми или бесперспективными результатами, обогащаясь за счет минимизации своих расходов на такое исследование до того момента, когда скрывать неудачность соответствующих ИиР будет уже невозможно.

Наверное, небезосновательно за примерами осуществления заведомо бесперспективных
ИиР адресуют к оборонным НИОКР, осуществляемым по директивным тематикам. Установлено, что в оборонной сфере НИОКР должны продолжаться не более 2-3 лет, так как при большей продолжительности они теряют свою актуальность. По результатам проверки Счетной Палаты в конце 1990-х - начале 2000-х гг. отставание от первоначальных сроков реализации НИОКР по ряду научных и конструкторских тем составляло 8-13 лет. В 2009 г. начальник Генштаба ВС РФ Н. Макаров признался, что на тот год по ряду тем имеется отставание на 10-15 лет [9]. Тестированию на заведомую бесперспективность подлежит продолжавшийся 25 лет совместный российско-украинский проект создания среднего транспортного самолета Ан-70, который был закрыт только после прекращения в 2014 г. российско-украинского военно-технического сотрудничества [13]. При этом по данным только на 2011 г. Россия израсходовала на финансирование данного проекта 1,1 млрд. долл. США [6]. Другим ярким примером ИиР, попадающих в данную категорию, могла бы стать реализация проекта создания танка «нового поколения» Т-95, который был закрыт только в 2010 г., т.е. через 17 лет после начала работ. Очевидно, что НПО Уралвагонзавод, занимавшееся данным проектом, да и его кураторы из Минобороны, давно знали о непомерно высокой цене танка (400 млн. руб. против 71 млн. 915 тыс. за танк T-90A), в том числе из-за которой Минобороны в итоге отказался от закупки данного изделия [23].

4. Наличие системы «самогосзаказа», состоящей в том, что исполнитель ИиР, финансируемых за счет средств бюджета, сам выступает заказчиком этих Ии Р.

Система самогосзаказа является частью современной системы формирования для исследовательских организаций госзадания в сфере научной деятельности, финансируемого за счет субсидии на финансовое обеспечение выполнения государственных работ в сфере научной деятельности. Она состоит в отборе проектов по инициативным тематикам, т.е. тематикам, разработанным научным учреждением (организацией-исполнителем ИиР), производимом самим этим учреждением по результатам внутреннего конкурса научных проектов [11].

Системой самогосзаказа является отбор научных проектов по внутренним конкурсам на соискание внутренних научно-исследовательских грантов, финансируемых из внебюджетных 
средств, проводимый, в частности, вузами [16].

К системе самогосзаказа ИиР фактически относятся закупки ИиР внутри госкомпаний, обязанных по инициативе Президента РФ с 2011 г. принимать (актуализировать) и реализовывать у себя программы инновационного развития, в том числе программы ИиР, когда, например, дочернее или зависимое производственное предприятие компании с госучастием заказывает ИиР специализированной научно-исследовательской организации из числа дочерних или зависимых обществ данной госкомпании.

Очевидно, система самогосзаказа предоставляет недобросовестному исполнителю ИиР наибольшие возможности по необоснованному обогащению за счет государственных средств, так как в этом случае представители ФОИВ не принимают участия ни в отборе тематики ИиР, ни в определении полученной новизны. В связи с этим фальсификация ИиР может быть проведена исполнителем значительно более грубо и, следовательно, со значительно меньшими затратами, что обеспечивает большее обогащение. Более того, может иметь место прямой подлог результатов ИиР (подлог - материализованное искажение истины, подделка документов [15], например, когда отчет о ИиР представляет собой набор хотя и научных текстов, но не относящихся к теме исследования.

Намеками на масштабную практику фальсификации ИиР в госкомпаниях полны результаты официальных проверок, хотя они, как правило, не приводят к заведению уголовных дел. Так, Счетная Палата установила, что из 80,5 млрд. руб. расходов на НИОКР Роскосмоса, проверенных в 2014 г., расходы на сумму 71,6 млрд. были отражены в учете некорректно. Отсутствовал бухгалтерский учет нематериальных активов, опытных образцов и материальных ценностей, полученных в ходе проведения НИОКР. Как деликатно отмечается в акте Счетной Палаты, «низкое качество учета результатов НИОКР не исключает повторного использования научных разработок прошлых лет в качестве отчетов при исполнении вновь заключенных госконтрактов» [7]. Заметим, что речь шла о возможности фальсификации ИиР в форме самоплагиата.

Все же по результатам проверок госкомпаний меньшего масштаба уголовные дела, связанные с хищениями средств, выделяемых на ИиР, заводятся. Такие хищения несколько лет назад были выявлены в ОАО «Российские космические системы» (РКС), которое является исполнителем работ по Федеральной целевой программе ГЛОНАСС (программе развития одноименной российской навигационной спутниковой системы). Более трети работ (37\% госзаказа в 2007 г., 38 - в 2008) по госконтрактам РКС осуществляли $3 А О$ «НПО космического приборостроения» и ООО «Синертек» в виде НИОКР. Стоимость НИОКР завышалась. В 2007-2010 гг. на счета данных фирм были переведены 3,2 млрд. руб. При этом никаких помещений для осуществления работ у двух исследовательских организаций, зарегистрированных по тому же адресу, что и сама РКС, не было, а 1100 сотрудников, которые «работали» над исполнением НИОКР и на оплату труда которых списывались деньги, были сотрудниками самих РКС [21].

5. Значительная сложность для заказчика ИиР определить стоимость (объем) ИиР, необходимых для получения результата, зафиксированного в госзаказе, а также проверить объем ИиР, осуществленных по его заказу. Первое объясняется уникальностью Ии Р. Как справедливо отмечают Н.С.Белогина и А.С.Попова, разработки имеют уникальный характер, поэтому не существует расценок или нормативных документов по определению стоимости ИиР [1]. Второе объясняется интеллектуальным характером ИиР, обусловливающим их скрытость от внешнего наблюдения. Объем осуществленных ИиР может быть точно определен лишь по данным внутреннего учета, осуществляемого исполнителем Ии Р. Но на практике соответствующие данные не включаются в состав результатов ИиР, подлежащих передаче заказчику, например не указываются как таковые в техническом задании на исполнение ИиР [5], очевидно, потому, что у заказчиков все равно нет возможности проверить эти сведения, что снижает их ценность. По результатам же внешнего наблюдения, объектом которого являются статьи в научных журналах, отчеты о научно-исследовательской или опытно-конструкторской работе, можно лишь весьма косвенно судить об объеме проделанной исполнителем работы. Иная ситуация имеет место при заказе других товаров. Здесь как раз по реально поддающимся проверке со стороны заказчика результатам можно достаточно точно судить об объеме выполненных исполнителем работ. Так, об объеме образовательных услуг, предоставленных вузом, можно весьма точно судить по данным о численности обучающихся всего, их 
численности по формам обучения (очная, заочная), образовательным программам (бакалавриат, специалитет, магистратура, аспирантура).

Рассмотренное обстоятельство позволяет исполнителю работ завышать стоимость ИиР, в том числе в ходе выполнения ИиР под видом перерасхода средств, оговоренных в госконтракте.

6. Значительно более высокий уровень налоговых льгот за осуществление Ии Р. Налоговое финансирование ИиР в 2017 г. составило 143,1 млрд. руб. [4, с. 47-48]. По оценкам Минфина, в 2017 г. общая величина потерь бюджета от налоговых льгот составила 2,5 трлн. руб. [22]. Отсюда, налоговые льготы по ИиР составили 5,7\% $\left(0,1431 / 2,5^{*} 100\right)$ от общей величины льгот. Но внутренние затраты на ИиР составили лишь 1,1\% ВВП [19], т.е. уровень налоговых льгот за осуществление ИиР превышал в 2017 г. средний по стране более чем в 5 раз $(5,7 / 1,1=5,2)$.

Данное обстоятельство позволяет недобросовестным исполнителям бюджетных ИиР получать дополнительный доход за счет повышенных налоговых льгот. Очевидно, значительно более высокий уровень налогового финансирования ИиР выступает существенным стимулом к участию в исполнении госзаказа на Ии Р. Авторы «Национального доклада об инновациях в России 2016», отмечая в связи с резким ростом расходов на ИиР в ПАО «НК «Роснефть» и ПАО «ТАТНЕФТЬ» крайне низкое качество патентов у всех российских компаний (их невостребованность в дальнейших разработках и в России, и за рубежом), предположили, что причиной такой ситуации может быть, в частности, «формальный подход к НИОКР», когда НИОКР нацелены больше на отчетность (в частности, в рамках программы инновационного развития) и получение налоговых льгот [10, с. 40].

Рассмотренные выше обстоятельства лишь создают дополнительные возможности для не- обоснованного обогащения при поставках для госнужд ИиР по сравнению с поставками других товаров. Использовать же их позволяют условия, в которых осуществляются поставки ИиР по госзаказу. К таким условиям относится, прежде всего, низкое качество заказчика ИиР для госнужд. Можно выделить факторы, его обусловливающие:

1. Отсутствие адекватной системы учета результатов ИиР в стране, в том числе научной новизны диссертаций, и использования этих результатов при разработке госзаказа на ИиР и приемке их результатов.

2. Недостаток квалифицированных экспертов для научной экспертизы как на стадии формирования госзаказа на ИиР, так и на стадиях контроля за осуществлением и приемки результатов Ии Р.

3. Отсутствие адекватной системы контроля ФОИВ над самогосзаказом.

4. Коррумпированность чиновников в системе госзаказа Ии Р.

Очевидно, что в борьбе с оппортунистическим поведением науки в сфере госзаказа первостепенное значение должно быть уделено устранению этих факторов деградации «квалифицированного госзаказчика ИиР». Представляется, что главным условием его формирования у нас является стремительное развитие всего спектра наукоемких производств. Вызванный им высокий спрос на ИиР позволит решить проблему качества научных кадров, в частности его ухудшения из-за утечки за рубеж лучших ученых. Собственно развитие наукоемких производств приведет к появлению в них множества специалистов, заинтересованных в использовании результатов Ии Р. Все это позволит обеспечить необходимое качество как заказа ИиР, так и контроля за их исполнением и приемки их результатов.

\section{Библиографический список}

1. Белогина Н.С., Попова А.С. Проблемы выявления и снижения уровня рисков мошенничества с материалами при выполнении НИОКР // Международный студенческий научный вестник. - 2018. - № 2. - URL: http:// eduherald.ru/ru/article/view?id=18129.

2. Большой юридический словарь. Фальсификация / Под ред. А.Я. Сухарева, В.Е. Крутских.- М.: ИНФРА-М, 2003. - 703 с.

3. Вольное сетевое сообщество экспертов, исследователей и репортеров, посвящающих свой труд разоблачениям мошенников, фальсификаторов и лжецов. - URL: https://www.dissernet.org/.

4. Городникова Н.В., Гохберг Л. М., Дитковский К.А. и др. Наука. Технологии. Инновации: 2019: краткий статистический сборник.- М.: НИУ ВШЭ.-2019.- 84 с. 
5. Договор на выполнение научно-исследовательских и опытно-конструкторских работ (НИОКР) (примерная форма- URL: http://docs.cntd.ru/document/855100547.

6. Ищенко С. Недовооружённые силы России //Армейский вестник.- URL: https://army-news.ru/2011/03/ nedovooruzhyonnye-sily-rossii/.

7. Космические откаты Чемезова и Остапенко.- URL: https://wek.ru/kosmicheskie-otkaty-chemezova-iostapenko.

8. Милов Г. К чему приводит увеличение затрат на НИОКР // Ведомости.- URL: https://www.vedomosti.ru/ management/articles/2012/10/30/umnee_a_ne_bolshe.

9. Мясников В. Ненасытные НИОКР. Конструкторские разработки затягиваются до полного устаревания.URL: https://old.flot2017.com/item/monitoring/3676.

10. Национальный доклад об инновациях в России 2016.- М.: Минэкономразвития, Открытое правительство, PBK.-2016. - 99 с.

11. Об утверждении методических рекомендаций по распределению субсидий, предоставляемых федеральным государственным учреждениям, выполняющим государственные работы в сфере научной (научно-исследовательской) и научно-технической деятельности (Проект приказа Минобрнауки России) // ЭПС «Система ГАРАHT». - URL: base.garant.ru/56632760/.

12. Особенности закупки научно-исследовательских и опытно-конструкторских работ.- URL: https:// economuch.com/munitsipalnyiy-zakaz-gosudarstvennyiy/osobennosti-zakupki-nauchno-issledovatelskih-47847. html.

13. Отказ России от Ан-70: конец проекта? - URL: https://news.rambler.ru/politics/29400961-otkaz-rossii-otan-70-konets-proekta/.

14. «Петрикгейт» - скандал вокруг Виктора Петрика.- URL: https://newsland.com/community/4057/content/ petrikgeit-skandal-vokrug-viktora-petrika/2051247.

15. Подлог.-URL: https://dic.academic.ru/dic.nsf/ruwiki/393436.

16. Положение о конкурсе на соискание внутренних научно-исследовательских грантов - URL: 90345-polozhenie_o_grantah_iz_sredstv_universiteta_2018.pdf.

17. Порядков Л. Мошенничество в науке - URL: https://maxpark.com/user/1220335144/content/643159.

18. Примеры мошенничества. Мошенничество в науке. - URL: http://antifraud.narod.ru/fraud-example3.html.

19. Расходы стран на НИОКР.- URL: https://nonews.co/directory/lists/countries/research-developmentexpenditure.

20. Рекомендации участников IX Международного Форума «Инновационное развитие через рынок интеллектуальной собственности». г. Москва, 7.04.2017 г. Итоговый документ.- URL: http://structure.sfu-kras.ru/files/ structure/rniiis_itogi.pdf.

21. Романов А. Искусство воровства достигло в России космических высот.- URL: http://www.km.ru/vrossii/2013/05/17/finansovye-makhinatsii-i-afery/710970-iskusstvo-vorovstva-dostiglo-v-rossii-kosm.

22. Сикорский Д. Без льгот, но с ростом: Минфин пересмотрит политику финансового стимулирования. - URL: https://rueconomics.ru/258778-bez-lgot-no-s-rostom-minfin-peresmotrit-politiku-finansovogo-stimulirovaniya.

23. T-95 - мертворожденный монстр российского танкопрома. - URL доступа: http://alternathistory.com/t-95mertvorozhdennyj-monstr-rossijskogo-tankoproma/.

24. Трошин Д.В. Методы оценки результатов научно-исследовательских работ // Экономический анализ: теория и практика. - 2014. - № 46 (397). - С. 50-58.

25. Узнайте, как работает проверка на плагиат.- URL: https://antiplagiarism.net/ru/blogs/how-plagiarismdetection-works/.

26. Чечель А., Товкайло М. Эффективность госрасходов на НИОКР практически равна нулю. Результатом 1586 контрактов на 6,2 млрд. руб. в 2009 г. стали два незапатентованных программных обеспечения стоимостью 30 млн. руб.- URL: https://www.vedomosti.ru/politics/articles/2011/01/17/effektivnost_gosrashodov_na_niokr_ prakticheski_ravna_nulyu. 